\title{
Pengaruh Kualitas Pelayanan Terhadap Kepuasan Lansia (Studi Kasus di Desa Gledug Kabupaten Blitar)
}

\section{The Effect of Posyandu Cadre Service Quality on Elderly Satisfaction (The Case Study in Gledug Village, Blitar Regency)}

\author{
Fandi Sudiasmo, S.Sos., M.Si ${ }^{1}$, Novi Dwi Rengganis ${ }^{2}$ \\ 1 Fakultas Ilmu Sosial dan Ilmu Politik, Univ. Islam Balitar \\ Jl. Majapahit No. 2 - 4, Blitar, Indonesia \\ 2 Fakultas Ilmu Sosial dan Ilmu Politik, Univ. Islam Balitar \\ Jl. Majapahit No. 2 - 4, Blitar, Indonesia \\ Email: Fandysudiasmo@gmail.com
}

\begin{abstract}
ABSTRAK
Seiring perganitan waktu, secara kronlogis usia manusia akan terus bertambah. Dengan bertambahnya usia terjadi penurunan terhadap beberapa fungsi vital pada tubuh manusia. Contohnya seperti, menurunya fungsi pendengaran, kaburnya penglihatan, serta melemahnya kekuatan fisik. Ini merupakan fakta yang dialami oleh orang lanjut usia atau biasanya disebut dengan lansia. Pada saat ini lansia sudah diberikan fasilitas pelayanan posyandu lansia yang membantu lansia dalam menangani masalah kesehatannya. Dari pemikiran tersebut penelitian ini akan menggali pengaruh kualitas layanan kader posyandu terhadap kepuasan lansia serta kendala dan hambatan guna mencapai kepuasan tersebut. Berdasarkan penelitian yang diperoleh dari hasil SPSS uji pengaruh simultan (ujiF) menghasilkan bahwa nilai uji $\mathrm{T}$ adalah $\mathrm{T}_{\text {hitung }}(3,220)>\mathrm{T}_{\text {tabel }}$ $(2,007)$ dan signifikasinya $0,002<0,05$ maka $\mathrm{H}_{0}$ ditolak dan $\mathrm{H}_{1}$ diterima. Dari nilai tersebut ditarik kesimpulan bahwa kualitas pelayanan memiliki pengaruh terhadap kepuasan. Hal ini memperlihatkan bahwa terdapat hubungan secara signifikan antara kualitas pelayanan kader dengan kepuasan lansia. Pendekatan yang digunakan adalah metode deskriptif kuantitatif. Hasil yang didapatkan menunjukkan bahwa tingkat kepuasan lansia dalam menerima pelayanan yang diberikan kader sudah baik. Hal tersebut dipengaruhi oleh sikap ramah tamah kader, rasa kesopanan yang di lihat lansia dan tanggung jawab kader dalam memberikan pelayanan yang diterima dengan baik oleh lansia. Dari hasil pembahasan terdapat beberapa hambatan yang mempengaruhi kepuasan. Sehingga pelayanan perlu ditingkatkan lagi guna mencapai kepuasan lansia.
\end{abstract}

Kata Kunci : Kualitas Pelayanan, Kepuasan lansia

\section{ABSTRACT}

Over time, the human age will continue to increase chronologically. With increasing age there is a decrease in several vital functions in the human body. For example, such as decreased hearing function, blurred vision, and weakened physical strength. This is a fact experienced by the elderly or commonly referred to as the elderly. At this time the elderly have been provided with elderly 
posyandu service facilities that help the elderly in dealing with their health problems. From these thoughts, this research will explore the influence of posyandu cadre service quality on elderly satisfaction and the obstacles and barriers to achieving that satisfaction. Based on the research obtained from the results of the SPSS simultaneous effect test (F-test), it shows that the T-test value is T-count $(3,220)>$ T-table $(2,007)$ and the significance is $0.002<0.05$, so HO is rejected and $H 1$ is accepted. From this value, it is concluded that service quality has an influence on satisfaction. This shows that there is a significant relationship between the service quality of cadres and the satisfaction of the elderly. The approach used is quantitative descriptive method. The outcomes acquired show that the degree of satisfaction of the elderly in receiving services provided by cadres is good. This is influenced by the cadres' friendliness, the sense of politeness seen by the elderly and the responsibility of cadres in providing services that are well received by the elderly. From the results of the discussion, there are several obstacles that affect satisfaction. So that services should be improved again to accomplish to achieve elderly satisfaction.

Keyword: Service quality, Satisfaction.

\section{PENDAHULUAN}

Badan Pusat Statistik Nasional (BPPS) memprediksi terdapat peningkatan jumlah penduduk lanjut usia atau lansia pada tahun 2010 mencapai 9,77\% dari total penduduk, menjadi 11,34\% pada tahun 2020. Sedangkan, World Health Organization (WHO) menyatakan jumlah lansia di Indonesia di tahun 2020 mengalami pertumbuhan hingga angka 11,34 atau 28,8 juta orang. Menurut WHO rasio penduduk lansia pada populasi menunjukkan pertumbuhan sangat cepat terlebih pada wilayah Asia Tenggara (Bappenas, 2011). Indonesia merupakan negara pada kawasan Asia Tenggara yang yang memiliki riwayat angka kenaikan secara signifikan pada jumlah lansia, sehingga kualitas kesehatan memiliki peran penting dalam meningkatkan angka harapan hidup di Indonesia.

Ditingkat masyarakat, pelayanan kesehatan untuk lansia yaitu Posyandu Lansia. Sedangkan pelayanan kesehatan lansia pada tingkat dasar yaitu Puskesmas dan pada tingkat lanjut yaitu rumas sakit. Posyandu lansia adalah pos layanan terpadu yang diperuntukan bagi lansia pada suatau wilayah yang telah disepakati, dengan penggerak masyarakat untuk tujuan mendapatakan layanan kesehatan. Posyandu lansia bagian dari perkembangan kebijakan pemerintah dalam melayani kesehatan untuk masyarakat lanjut usia yang diselnggarakan dengan progam 
puskesmas yang pada pelaksanaanya melibatkan peran dari lansia, keluarga, tokoh masyarakat serta organisasi.

Menurut (Parasuraman at al., 1998) pengukuran kualitas pelayanan didasarkan pada 5 dimensi, yaitu :

1. Tangibles, artinya fakta aktual dari kepedulian serta perhatian yang telah diterima konsumen dari penyedia jasa.

2. Realibility, yaitu handal yang menunjukkan kemampuan perusahan dalam melakukan pelayanan jasa yang sesuai terhadap apa yang dijanjikan dengan ketepatan waktu.

3. Responsiveness, yaitu daya tanggap atau sebuah kapasitas perusahaan yang dilaksanakan oleh karyawan langsung didalam pemberian layanan secara cepat dan tanggap.

4. Assurance, yaitu keahlian dan tindakan employee dalam membentuk kepercayaan dan keyakinan untuk menggunakan jasa yang diberikan pada konsumen.

5. Empathy, yaitu kemampuan penyedia jasa dalam memberikan perhatian terhadap pengguna jasa secara individu, termasuk pada kepekaan terhadap kebutuhan pengguna jasa.

Menuru Kotler dalam Husaein (2005:286) terdapat berbagai teknik dalam pengukuran terhadap kepuasan pelanggan, diantaranya :

1. Complain and suggestion system (sistem keluhan dan saran).

2. Customer satisfaction surveys (survei kepuasan pelanggan)

3. Ghost shopping (pembeli bayangan)

4. Lost customer analysis (analisa pelanggan yang pergi)

Berdasarkan Gambar 1 kerangka berfikir penelitian yang menunjukkan pengaruh antara variabel bebas terhadap variabel terikat dalam kasus ini adalah pengaruh kualitas pelayanan lansia terhadap kepuasan.

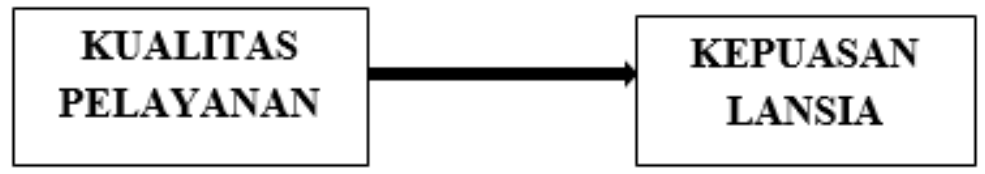

Gambar 1. Bagan Kerangka Berfikir

Dari teori yang telah dijelaskan sebelumnya, maka rumusan hipotesis dari penelitian yang akan dilaksanakan adalah sebagai berikut: 
Ho1 : Diduga tidak ada pengaruh pelayanan kader posyandu terhadap Kepuasan lansia.

Ha1 : Diduga ada pengaruh pelayanan kader posyandu terhadap kepuasan lansia.

\section{METODE PENELITIAN}

Metode yang digunakan pada kasus ini menggunakan metode deskriptif kuantitatif. Metode penelitian kuantitatif adalah pendekatan penelitian yang didasarkan pada filsafat positivism, yang dipergunakan dalam meneliti dengan sampel atau populasi tertentu (Sugiyono, 2012). Metode kuantitatif adalah metode ilmiah karena telah sesuai dengan kaidah ilmiah diantaranya, empiris atau konkirt, objektif, rasional, terukur, serta tersistematis. Alat bantu yang biasanya digunakan adalah program SPSS.

Metode survei digunakan pada penelitian ini untuk memberikan suatu batas yang jelas mengenai data untuk mengetahui hubungan atau pengaruh. Pengaruh yang dimakdud yaitu sebuah daya yang muncul dari berbagai hal yang mengakibatkan terbentuknya kepercayaan, watak, ataupun perbuatan seseorang (Sukmadinata, 2008).

Penelitian ini menggunakan populasi yang diambil dari masyarakat yang mengikuti posyandu lansia sebanyak 53 orang responden di Desa Gledug. Teknik digunakan untuk menentukan sampel yaitu dengan teknik sampel jenuh. Hal ini didasarkan pada jumlah populasi yang kurang dari 100 orang, sehingga digunakan sampel dari semua populasi yang ada (Arikunto, 2012).

Uji yang dipakai peneliti menggunakan berbagai macam uji. Uji yang pertama adalah Uji validitas yang dilakukan dengan tujuan untuk membuktikan sebarapa baik sebuah instrumen bisa dipergunakan dalam pengukuran konsep yang akan diukur. Pada uji ini juka hasil signifikansi lebih kecil dari 0,05, maka instrument yang digunakan dinayatakan valid, tetapi apabila hasil dari signifikansi lebih besar dari 0,05 maka instrumen dikatakan tidak valid (Sugiyono, 2012).

Selanjutnya Uji reabilitas yang merupakan lanjutan dari uji validitas, dimana unit yang termasuk pada uji ini yaitu item yang valid saja. Menurut Sekaran (dalam Rocmat Aldy Purnomo, 2017) dalam uji reabilitas apabila nilai 
koefisien $\alpha \leq 0.6$ adalah kurang baik, sedangkan $\alpha \geq 0.6$ maka instrument yang digunakan tersebut dapat dikatakan raliabel.

Uji Tahap berikutnya adalah uji asumsi klasik, antara lain dengan Uji Normalitas. Unutuk normalitas yang digunakan adalah Uji Skewness-Kurtosis. Uji ini digunakan agar dapat diketahui normalitas sebaran data penelitian, apabila taraf signifikan kurang dari -2 berarti data tersebut normal dana sebaliknya apabila taraf signifikan kurang +2 maka data terdistribusi tidak normal. Uji Normalitas dengan Skewnees-Kortunis mempunyai kelebihan dianatanya: pada uji ini dapat mengetahui grafik normalitas baik menceng ke kanan ataupun ke kiri, grafik dengan terlalu datar atau berkumpul ditengah atau disebut juga dengan ukuran kemencengan data.

Uji asumsi klasik yang lain yang digunakan adalah uji heteroskedastisitas. Uji Glejser adalah salah satu teknik dalam menguji heteroskedastisitas. Dalam uji Glejser yang digunakan melalui proses regresi variabel bebas pada nilai absolut residualnya. Untuk penarikan kesimpulan heteroskedastisitas dapat dilihat dari nilai 1 dengan probalitas sig $>0,05$ yang bermakna bahwa persamaan regresi tersebut tidak dapat terjadi heteroskedastisitas. Sebaliknya, apabila nilai 1 dengan probalitas sig $<0,05$ maka persamaan regresi tersebut terjadi heteroskedastisitas.

Tahap berikunya adalah tahap uji hipotes dengan menggunakan T-Test (Uji T). Sugiyono, (2008) menyebutkan uji T memiliki tujuan agar diketahui besarnya pengaruh setiap variabel independen yaitu kualitas produk dan promosi dengan individual atau parsial terhadap variabel dependen dalam memutuskan pembelian. Pada T-Test hasil output-nya dihasilkan melalui aplikasi SPSS berdasarkan pada tabel sig $<0,05$ yang bermakna bahwa variabel memiliki pengaruh secara signifikan.

\section{HASIL DAN PEMBAHASAN}

\section{Uji Instrument}

Uji instrument yang pertama menggunakan uji validitas, yang bertujuan untuk memperlihatkan ketepatan serta kecermatan suatu alat ukur, yang biasanya menggunakan kuesioner. Uji ini digunakan dengan membandingkan nila $\mathrm{r}$ hitung yang didapatkan dari hasil luaran nilai $r$ tabel. Apabila hasil $r$ hitung $>r$ tabel maka 
dinyatakan valid, namun apabila hasil $\mathrm{r}_{\text {hitung }}<\mathrm{r}_{\text {tabel }}$ maka dinyatakan tidak valid. Untuk menentukan nilai $r$ tabel dapat menggunakan kriteria sebagai berikut (Ikhsan, 2017):

1. Tingkat signifikansi $5 \%(0,05)$

2. Menentukan nilai df (degree of freedom), digunakan rumus $(\mathrm{df}=\mathrm{n}-2)$

Hasil statistik $\mathrm{r}$ tabel pada tingkat signikikansi 5\% $(0,05)$, dari jumlah responden $(n)=53$. Dengan persamaan $\mathrm{df}=\mathrm{n}-2$ sehingga dapat dihitung dengan $\mathrm{df}$ $=53-2=51$, maka didapatkan nilai $r_{\text {tabel }}=0,2241$.

Tabel. 1 Hasil Uji Validitas Kualitas Pelayanan

\begin{tabular}{|c|c|c|c|c|}
\hline $\begin{array}{c}\text { No. } \\
\text { Item }\end{array}$ & $\mathbf{r}_{\text {hitung }}$ & $\mathbf{r}_{\text {tabel }}$ & Sig. & keputusan \\
\hline $\mathrm{X} 1_{.1}$ & 0,681 & 0,2241 & 0,000 & Valid \\
\hline $\mathrm{X} 1_{.2}$ & 0,681 & 0,2241 & 0,000 & Valid \\
\hline $\mathrm{X} 1_{.3}$ & 0,703 & 0,2241 & 0,000 & Valid \\
\hline $\mathrm{X} 1_{-4}$ & 0,751 & 0,2241 & 0,000 & Valid \\
\hline $\mathrm{X} 1_{.5}$ & 0,326 & 0,2241 & 0,017 & Valid \\
\hline
\end{tabular}

Dari hasil pengujian terhadap validitas kualitas pelayanan, terlihat di Tabel 1 tersebut menunjukkan nilai $\mathrm{r}_{\text {hitung }}>\mathrm{r}_{\text {tabel }}(0,2241)$ serta hasil porbabilitas untuk tiap item untuk variabel adalah 0,000 dan 0,017 <0,05, hal ini menegaskan bahwa butir pertanyaan yang digunakan pada setiap variabel dapat dinyatakan valid.

Tabel 2. Uji Validitas Kepuasan Lansia

\begin{tabular}{|l|l|l|l|l|}
\hline $\begin{array}{l}\text { No. } \\
\text { Item }\end{array}$ & $\mathbf{r}_{\text {hitung }}$ & $\mathbf{r}_{\text {tabel }}$ & Sig. & keputusan \\
\hline Y1 $_{-1}$ & 0,559 & 0,2241 & 0,000 & Valid \\
\hline Y1 $_{-2}$ & 0,642 & 0,2241 & 0,000 & Valid \\
\hline Y1.3 & 0,792 & 0,2241 & 0,000 & Valid \\
\hline Y1 .4 & 0,741 & 0,2241 & 0,000 & Valid \\
\hline Y1 .5 & 0,424 & 0,2241 & 0,002 & Valid \\
\hline
\end{tabular}

Untuk uji validitas kepuasan lansia yang telihat dalam Tabel 2, terlihat bahwa nilai $r_{\text {hitung }}>r_{\text {tabel }}(0,2241)$ dan nilai serta hasil porbabilitas untuk tiap item untuk variabel adalah 0,000 dan 0,002 <0,05, hal ini menunjukkan semua bahwa butir pertanyaan yang digunakan pada setiap variabel dapat dinyatakan valid.

Uji instrument selanjutnya yaitu uji reliabilitas. Uji reliabilitas dapat dipergunakan untuk melihat sejauh mana nilai dari pengukuran menunjukan hasil yang stabil atau relatif konsisten. Hasil uji reabilitas digunakan koefisien 
Cronbach Alpha, yang melihat instrumen varibel dikatakan reliable apabila hasil nilai Cronbach Alpha sama dengan 0,06 atau lebih.

Tabel 3. Uji Reliabilitas

\begin{tabular}{|l|c|c|}
\hline \multicolumn{1}{|c|}{ Variabel } & \multicolumn{1}{|c|}{$\begin{array}{c}\text { Cronbach } \\
\text { Alpha }\end{array}$} & Keterangan \\
\hline Tangible/Bukti fisik & 0,625 & Reliable \\
\hline Reliability/ Kehandalan & 0,625 & Reliable \\
\hline Responsiveness/ Daya Tanggap & 0,625 & Reliable \\
\hline Assurance/ Keyakinan & 0,625 & Reliable \\
\hline Emphatic/ Empati & 0,625 & Reliable \\
\hline Kepuasan Lansia & 0,622 & Reliable \\
\hline
\end{tabular}

Berdasarkan hasil pengujian realiabilitas pada Tabel 3, menunjukkan bahwa hasil Cronbach Alpha dari seluruh variabel > 0,6, maka didapat kesimpulan bahwa seluruh instrumen setiap variabel dapat dikatakan reliable. Dengan kata lain, semua jawaban yang diberikan ke responden terhadap pertanyaan-pertanyaan yangdigunakan dalam mengukur semua variabel adalah konsisten dan dapat dipercaya (reliable).

\section{Uji Asumsi Klasik}

Pada uji klasik, digunakan pengujian normalitas dan uji heteroskedastisitas. Untuk uji normalitas terlihat di Tabel 4 nilai Skewness pada semua variabel yang diolah menghasilkan nilai 0,789, sedangkan nilai yang ada di Kurtosis pada semua variabel yang diolah sebesar 0,652. Nilai Skewness dan Kurtosis pada variabel tangible / bukti fisik $\left(\mathrm{X}_{1}\right)$, realibility / kehandalan $\left(\mathrm{X}_{2}\right)$, responsiveness / daya tanggap $\left(\mathrm{X}_{3}\right)$, assurance / keyakinan $\left(\mathrm{X}_{4}\right)$, emphaty /empati $\left(\mathrm{X}_{5}\right)$, serta kepuasan wisatawan (Y) menunjukkan bahwa nilai tersebut berada pada nilai -2 sampai dengan +2 , sehingga dari hasil uji tersebut maka kesimpulanya adalah data penelitian berdistribusi normal dan asumsi normalitas terpenuhi.

Tabel 4 Hasil Uji Normalitas

\begin{tabular}{|ll|r|}
\hline \multicolumn{2}{|c|}{ One-Sample Kolmogorov-Smirnov Test } \\
\hline $\mathrm{N}$ & $\begin{array}{r}\text { Unstandardized } \\
\text { Residual }\end{array}$ \\
Normal Parameters, & Mean & 53 \\
& Std. Deviation &, 0000000 \\
Most Extreme Differences & Absolute & 2,27908826 \\
& Positive &, 090 \\
Kolmogorov-Smirnov Z & Negative &, 083 \\
Asymp. Sig. (2-tailed) & &,- 090 \\
a. Test distribution is Normal. & &, 652 \\
b. Calculated from data. &, 789 \\
\hline
\end{tabular}


Hasil Uji Asumsi klasih berikunya adalah Uji heteroskedastisitas. Dari tabel 5 terlihat nilai signifikansi variabel tangible $(\mathrm{X})$ terhadap kualitas pelayanan sebesar 0,449, memperlihatkan bahawa hasil signifikan dari setiap variabel lebih besar dari 0,05, sehingga ditarik kesimpulan model regresi yang diajukan tidak terjadi heteroskedastisitas.

Tabel 5. Hasil Uji Heterokedastistitas

\begin{tabular}{|c|c|c|c|c|c|c|}
\hline \multicolumn{7}{|c|}{ Coefficients $^{\mathrm{a}}$} \\
\hline \multirow{2}{*}{\multicolumn{2}{|c|}{ Model }} & \multicolumn{2}{|c|}{$\begin{array}{c}\text { Unstandardized } \\
\text { Coefficients }\end{array}$} & \multirow{2}{*}{$\begin{array}{c}\text { Standardized } \\
\text { Coefficients } \\
\text { Beta }\end{array}$} & \multirow[b]{2}{*}{$\mathrm{T}$} & \multirow[b]{2}{*}{ Sig. } \\
\hline & & $\mathrm{B}$ & Std. Error & & & \\
\hline \multirow[t]{2}{*}{1} & (Constant) &, 253 & 2,068 & & ,123 & ,903 \\
\hline & Kualitas Pelayanan &, 073 &, 096 & , 106 & ,762 & 449 \\
\hline
\end{tabular}

a. Dependent Variable: Abs_Res

\section{Uji Hipotesis}

Pada uji hipotesis menggunakan Uji T atau T-Test. Sugiyono (2008), menyebutkan T-Test memiliki tujuan agar diketahui besarnya pengaruh setiap variabel independen yaitu kualitas produk serta promosi dengan individual (parsial) terhadap variabel dependen keputusan untuk membeli. Hasil uji ini dapat dilihat menggunakan SPSS, apabila sig $<0.05$ maka dinyatakan bahwa varibel memiliki pengaruh secara signifikan.

Tabel 6. Hasil pengujian Uji Pengaruh Parsial

Coefficients $^{a}$

\begin{tabular}{|rl|r|r|r|r|r|}
\hline \multirow{2}{*}{ Model } & \multicolumn{2}{|c|}{$\begin{array}{c}\text { Unstandardized } \\
\text { Coefficients }\end{array}$} & $\begin{array}{c}\text { Standardized } \\
\text { Coefficients }\end{array}$ & & \\
\cline { 3 - 5 } & & $\mathrm{B}$ & Std. Error & Beta & \multicolumn{1}{c|}{$\mathrm{t}$} & Sig. \\
\hline \multirow{2}{*}{1} & 9,118 & 3,528 & & 2,584 &, 013 \\
& (Constant) &, 528 &, 164 &, 411 & 3,220 &, 002 \\
\hline
\end{tabular}

a. Dependent Variable: Kepuasan Lansia

Dari tabel 6 dapat terlihat bahwa pengaruh variabel kualitas pelayanan terhadap kepuasan lansia menunjukkan hasil signifikansi bernilai 0,002 lebih kecil dari taraf signifikan 0,05 dengan nila $\mathrm{T}_{\text {hitung }}$ sebesar 3,220 lebih besar dari $\mathrm{T}_{\text {tabel }}$ sebesar 2,007. 
Penelitian ini dilakukan berdasarkan kuesioner yang diisi oleh 53 responden lansia yang mengikuti kegiatan posyandu lansia. Dari hasil penelitian didapatkan pernyataan bahwa variabel kualitas pelayanan memiliki pengaruh positif terhadap kepuasan lansia. Hal ini menunjukkan persepsi kualitas pelayanan yang baik memiliki pengaruh terhadap kepuasan lansia. Maka, semakin baik kualitas layanan mengakibatkan para lansia merasa sangat puas terhadap pelayanan kadernya.

Hasil uji instrument variabel kepuasan pelayanan menunjukan indikator dari variabel kualitas pelayanan yang memiliki pengaruh paling signifikan terhadap kepuasan lansia adalah indikator assurance/jaminan atau keyakinan, hal ini dikarenakan kader posyandu selalu ramah dalam memberikan pelayanan, mendengarkan lansia dalam menyampainkan keluhannya dan tanggung jawab atas apa yang sudah ditugaskan. Dengan ini para lansia tidak segan akan bercerita tentang keluhannya dan merasa nyaman. Para lansia juga merasa percaya akan pelayanan yang diberikan oleh kader.

Sedangkan untuk indikator kualitas pelayanan yang mempunyai pengaruh paling sedikit adalah adalah reliability/kehandalan, hal ini dikarenakan para lansia yang merasa menunggu terlalu lama untuk mendapatkan pelayanan. Pelayanan yang dilakukan para kader merupakan faktor yang sangat berperan bagi lansia dalam memanfaatkan kegiatan posyandu. Pelayanan yang berkualitas merupakan bagian terpenting dalam memuhi kebutuhan orang yang sesuai dengan patokannya.

Seperti saat ini penampilan, kehandalan, ketanggapan, jaminan dan empati kader posyandu dalama memberikan pelayanan adalah faktor utama yang memberikan kesan sehingga akan dirasakan para lansia selama mendapatkan pelayanan yang diberikan kader posyandu. Maka dengan begitu akan timbul persepsi para lansia sebagai pengguna jasa terhadap kualitas layanan yang didapatkan. Persepsi terkait kualitas layanan yang baik secara tidak langsung mengakibatkan timbulnya rasa puas yang didapatkan para lansia, rasa percaya bahkan loyalitas, sehingga dapat mendukung terwujudnya strategi posyandu dan ketercapaian tujuan posyandu. 


\section{KESIMPULAN DAN SARAN}

Berdasarkan penelitian yang diperoleh melalui menghasilkan bahwa taraf signifikasinya $0,002<0,05$ maka $\mathrm{H}_{0}$ ditolak dan $\mathrm{H}_{1}$ diterima. Artinya adanya pengaruh yang signifikan dan positif antara kualitas pelayanan kader posyandu terhadap kepuasan lansia.

Saran yang bisa diberikan untuk berbagai pihak terkait dengan kualitas pelayanan kader terhadap kepuasan lansia antara lain kader terus pertahankan kualitas pelayanan yang sudah bagus dan tingkatkan ketepatan waktu agar lansia tidak menunggu terlalu lama dalam memberikan pelayanan. Sedangkan untuk penelitian selanjutnya agar dapat lebih meneliti lagi indikator variabel yang dapat menyebabkan lansia puas dengan pelayanannya.

\section{DAFTAR PUSTAKA}

Aldy Rochmat, Purnomo. (2016). Analisis Statistik Ekonomi dan Bisnis dengan SPSS. Yogyakarta: Fadilatama.

Arikunto, Suharsimi. (2012). Prosedur Penelitian Suatu Pendekatan Praktek. Jakarta: Rineka Cipta

Husein Umar. (2005), Metode Penelitian Untuk Tesis Dan Bisnis. Jakarta: Grafindo Persada.

Parasuraman, V. A. Zeithaml\& L. L. Berry,1998, "The Behavioral Consequences of Service Quality". Journal of Marketing (EBSCO) vol. 60 no. 2.

Sugiyono. (2008). Metode Penelitian Administrasi. Cetakan Ke-20.Penerbit Alfabeta. Bandung. Alfabeta.

Sukmadinata, Nana. 2008. Metode Penelitian Pendidikan. Bandung: PT. Remaja Rosdakarya. 